\title{
Hydrodynamic performance and heat generation by centrifugal pumps
}

Citation for published version (APA):

Ganushchak, Y. M., van Marken Lichtenbelt, W., van der Nagel, T., \& de Jong, D. S. (2006).

Hydrodynamic performance and heat generation by centrifugal pumps. Perfusion, 21(6), 373-379. https://doi.org/10.1177/0267659106074003

Document status and date:

Published: 01/01/2006

DOI:

10.1177/0267659106074003

Document Version:

Publisher's PDF, also known as Version of record

Document license:

Taverne

\section{Please check the document version of this publication:}

- A submitted manuscript is the version of the article upon submission and before peer-review. There can be important differences between the submitted version and the official published version of record.

People interested in the research are advised to contact the author for the final version of the publication, or visit the DOI to the publisher's website.

- The final author version and the galley proof are versions of the publication after peer review.

- The final published version features the final layout of the paper including the volume, issue and page numbers.

Link to publication

\footnotetext{
General rights rights.

- You may freely distribute the URL identifying the publication in the public portal. please follow below link for the End User Agreement:

www.umlib.nl/taverne-license

Take down policy

If you believe that this document breaches copyright please contact us at:

repository@maastrichtuniversity.nl

providing details and we will investigate your claim.
}

Copyright and moral rights for the publications made accessible in the public portal are retained by the authors and/or other copyright owners and it is a condition of accessing publications that users recognise and abide by the legal requirements associated with these

- Users may download and print one copy of any publication from the public portal for the purpose of private study or research.

- You may not further distribute the material or use it for any profit-making activity or commercial gain

If the publication is distributed under the terms of Article $25 \mathrm{fa}$ of the Dutch Copyright Act, indicated by the "Taverne" license above, 


\title{
Hydrodynamic performance and heat generation by centrifugal pumps
}

\author{
Y Ganushchak ${ }^{1}$, W van Marken Lichtenbelt ${ }^{2}$, T van der Nagel $^{3}$ and DS de Jong ${ }^{1}$ \\ ${ }^{1}$ Department of Extra-Corporeal Circulation, University Hospital Maastricht, Maastricht, the Netherlands; \\ ${ }^{2}$ Department of Human Biology, Maastricht University, Maastricht, the Netherlands; \\ ${ }^{3}$ Department of Cardio-Thoracic Surgery, University Hospital Maastricht, Maastricht, the Netherlands
}

For over a century, centrifugal pumps (CP) have been used in various applications, from large industrial pumps to flow pumps for aquariums. However, the use of CP as blood pumps has a rather short history. Consequently, the hydraulic performance data for a blood CP are limited. The aim of our investigation was to study the hydraulic performance and the heat generation of three commercially available CP: Bio-Medicus Bio-Pump BP80 (Medtronic), Rotaflow (Jostra Medizintechnik), and DeltaStream ${ }^{\mathrm{TM}}$ DP2 (MEDOS Medizintechnik AQ).

The study was performed using a circuit primed with a water-glycerin mixture with a dynamic viscosity of $0.00272 \mathrm{pa} / \mathrm{s}$. Pressure-flow curves were obtained by a stepwise stagnation of the pump outlet or inlet. The temperature changes were observed using ThermaCAM SC2000 (Flir Systems).

The pumps' performance in close to clinical conditions ('operating region') was analysed in this report. The 'operating region' in the case of the BP80 is positioned around the pressure-flow curve at a pump speed of $\mathbf{3 0 0 0}$ rpm. In the case of the Rotaflow, the 'operating region' was between the pump pressure-flow curves at a speed of 3000 and $4000 \mathrm{rpm}$, and the DP2 was found between 7000 and 8000 rpm.

\section{Introduction}

For over a century, centrifugal pumps (CP) have been used in various applications. The exploitation of industrial pumps is regulated by the extended set of rules and instructions based on the exact knowledge of the hydrodynamic characteristics of each specific pump. However, the use of CP as blood pumps has a rather short history. The majority of CP used for extracorporeal circulation (ECC) are non-metallic, volute pumps. ${ }^{1}$ These pumps are preferred for ECC because they do not have a mechanical seal, and are considered leak proof.

Address for correspondence: Y Ganushchak, MD, PhD, EKP, Department of Extra-Corporeal Circulation, University Hospital Maastricht, P. Debyelaan 25, PO Box 5800, 6202 AZ Maastricht, the Netherlands.

E-mail: yga@scpc.azm.nl
The standard deviation of mean pressure through the pump was used to characterise the stability of the pump. In experiments with outlet stagnation, the BP80 demonstrated high negative association between flow and pressure variability $(r=-0.68, p<0.001)$. In experiments with the DP2, this association was positive $(r=$ $0.68, p<0.001$ ). All pumps demonstrated significantly higher variability of pressure in experiments with inlet stagnation in comparison to the experiments with outlet stagnation.

The rise of relative temperature in the inlet of a pump was closely related to the flow rate. The heating of fluid was more pronounced in the 'zero-flow' mode, especially in experiments with inlet stagnation.

In summary, (1) the 'zero-flow' regime, which is described in the manuals of some commercially-available pumps, is the use of the pump outside the allowable operating region. It is potentially dangerous and should, therefore, never be used in clinical settings. (2) Using centrifugal pumps for kinetic-assisted venous return can only be performed safely when the negative pressure at the inlet of the pump is monitored continuously. The maximum allowable negative pressure has to be defined for each type of pump, and must be based on pump performance. Perfusion (2006) 21, 373-379.

CP have several advantages over the roller pump. It is believed that they do not produce high pressures when tubing is temporarily obstructed or kinked, do not produce spatulated emboli from compression of the tubing, and cannot pump large gas emboli. However, as everywhere in nature, the advantages are accompanied by disadvantages. The most important disadvantages are that the pump has to operate inside a narrow area of pressure-flow curve, and it has a tendency to heat the pumped fluid. $^{2}$

The aim of our study was to evaluate the hydrodynamic performance and heat generation of some commercially-available CP (Bio-Medicus B io-Pump BP80, Medtronic, Rotaflow, Jostra Medizintechnik, and DeltaStream ${ }^{\mathrm{TM}} \mathrm{DP} 2$, MEDOS Medizintechnik $\mathrm{AQ}$ ) in the controlled experimental condition. 


\section{Materials and methods}

The study was performed using a set primed with a water-glycerin mixture with a dynamic viscosity of $0.00272 \mathrm{pa} / \mathrm{s}$, which corresponds to the viscosity of blood with a Hct of $25 \%$ (Figure 1). The speed of each pump in the study was changed stepwise (by $1000 \mathrm{rpm}$ ) from $1000 \mathrm{rpm}$ to the maximum allowed by the drive console. The flow rate was changed in steps of $1 \mathrm{~L} / \mathrm{min}$ by gradual stagnation of the pump outlet or inlet ${ }^{3}$ for each pump speed. After stabilisation, the flow, and inlet and outlet pressures were recorded by Windaq software (DtaQ Instruments, Inc). A distribution of temperature in the CP was observed by infrared camera (ThermaCAM SC2000, Flir Systems). The average relative temperatures before a pump (AR01) and at the inlet of a pump (AR02, eye of an impeller) were analysed for each pump in the study (Figure 2). The relative temperature at the base of the pump (AR03) was analysed only for the DeltaStream ${ }^{\mathrm{TM}}$ DP2, because of a persistent hot area at the base of the pump, absent in other pumps included in the study. The average relative temperature at the AR01 was used for the standardisation of findings for the different pumps. All temperatures in this study are presented as a difference between the relative temperature at the AR01 and the AR02 inside the pump.

The 'operating region' was projected on the pressure flow-curves for each pump in the study. The 'operating region' was defined by the range of pre-oxygenator pressures and flows. For the set used in the University Hospital Maastricht for adult patients, the pre-oxygenator pressure was in the range of $280-390 \mathrm{mmHg}$ at flows from 3.9 to $5.2 \mathrm{~L} / \mathrm{min}$. The pumps' performance inside or close to the 'operating region' were analysed in this report. The 'operating region' in case of BP80 was positioned around the pressure-flow curve at a pump speed of $3000 \mathrm{rpm}$ (Figure 3a). In the case of a Rotaflow, the 'operating region' was between the pump pressure-flow curves at speeds of 3000 and $4000 \mathrm{rpm}$ (Figure 3b), and for DP2 it was found to be between 7000 and $8000 \mathrm{rpm}$ (Figure 3c).

All data are presented as mean \pm standard deviation of the mean. One-way ANOVA procedure was used for the comparison of mean values. Pearson's correlation coefficient was used to measure an association between temperature changes and hydrodynamic data. A $p$ value $<0.05$ was considered to indicate statistical significance.

\section{Results}

The pressure-flow curves for each pump in the study are presented in Figure 3.

The shut-off pressure (ie, pressure developed by a pump at complete outlet occlusion) for the $\mathrm{BP} 80$ at $3000 \mathrm{rpm}$ was $547.6 \pm 12.7 \mathrm{mmHg}$. This value was significantly higher than the shut-off pressure for the Rotaflow at $3000 \mathrm{rpm}$ (333.5 \pm

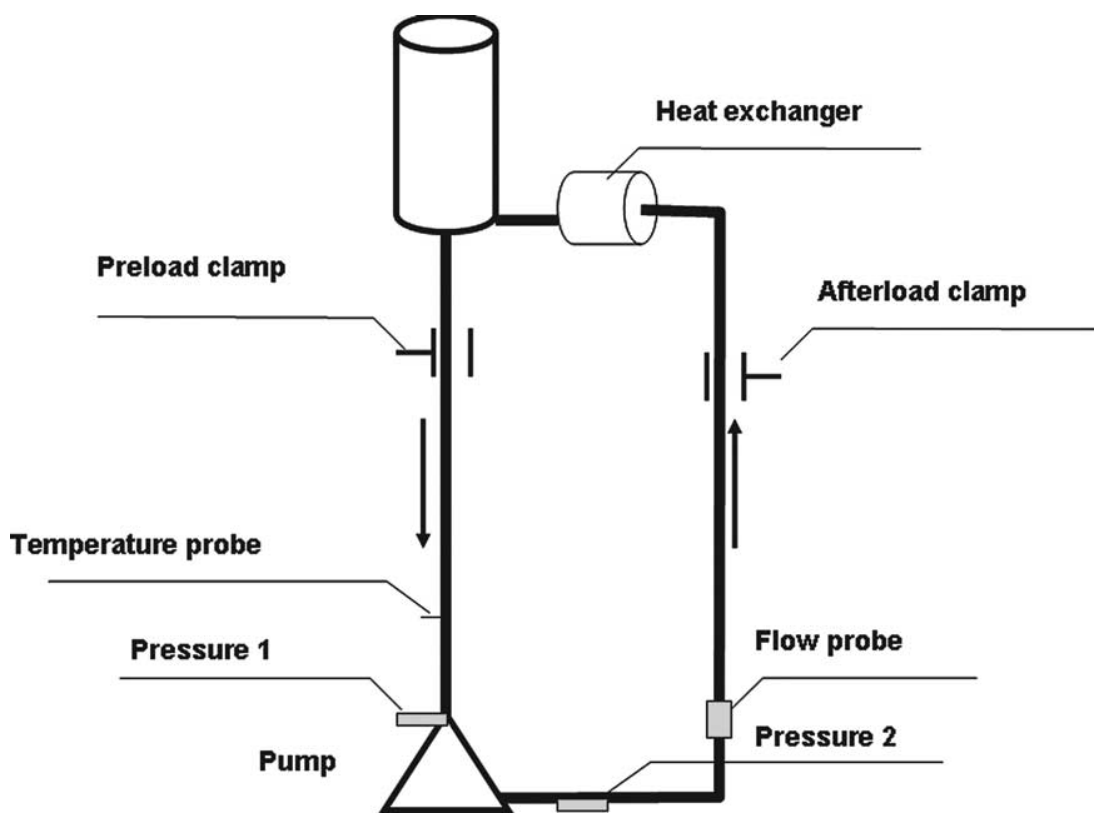

Figure 1 The circuit diagram for centrifugal pump evaluation. Pressure 1 - pressure at the inlet of the pump; Pressure 2 - pressure at the outlet of the pump (Truwave PX - 600F pressure transducer, Edwards Lifesciences LLC, Irvine, USA). Flow probe - flow measurement in circuit (HT207 medical flowmeter, Transonic System Inc., NY, USA). 

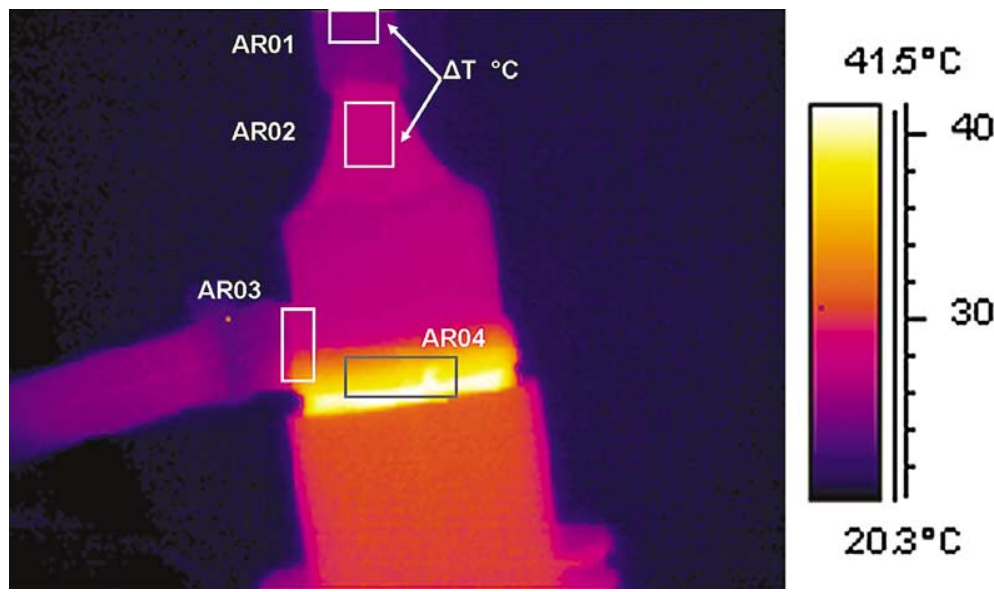

Figure 2 Infrared image of DeltaStream ${ }^{\mathrm{TM}} \mathrm{DP} 2$. The average relative temperatures in marked areas were taken in analysis for each pump in the study. AR01 - the area before pump. AR02 - area at the inlet of the pump (eye of an impeller). AR03 - base of the pump. AR03 was analysed only for the DeltaStream ${ }^{\mathrm{TM}} \mathrm{DP} 2$, because of persistent hot area at the base of the pump, absent in other pumps included in the study.

$1.3 \mathrm{mmHg}, p<0.001)$, and the DP2 at a pump speed of $7000 \mathrm{rpm}(360.8 \pm 2.8 \mathrm{mmHg}, p<0.01)$. In experiments with inlet stagnation, the BP80, at a pump speed of $3000 \mathrm{rpm}$, the inlet pressure decreased to $-517.4 \pm 8.7 \mathrm{mmHg}$. With similar conditions, the RTF and DP2 demonstrated significantly less negative pressure at the inlet of the pump $(-284.3 \pm 1.9$ and $-266.9 \pm 109.4 \mathrm{mmHg}$, respectively, $p<0.01$ in comparison to the BP80).

The standard deviation of mean pressure through the pump was used to characterise the stability of the pump (Figure 4). In the case of the BP80, at a pump speed of $3000 \mathrm{rpm}$, the mean value of the pressure standard deviation was $3.3 \pm 1.5 \mathrm{mmHg}$. The Rotaflow had a significantly more stable flow at this condition $(1.5 \pm 0.4 \mathrm{mmHg}, p<0.001)$. The DP2 also demonstrated a lower variability of pres-

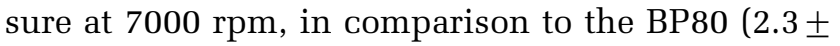
$0.4 \mathrm{mmHg}, p<0.05)$. There was no statistically significant difference in stability of pressure between the Rotaflow and the DP2.

In our experiments with flows higher than $4.0 \mathrm{~L} / \mathrm{min}$, the BP80 performance was relatively stable (the standard deviation of pressure was $2.4 \pm 0.5 \mathrm{mmHg}$ ) and only with decreasing of flow (increasing of outlet stagnation) did the pump become progressively unstable (Figure 4). Pearson's correlation coefficient yielded a high negative association of pressure variability and flow for the BP80 $($ rtcgqa $=-0.68, p<0.001)$.

DP2 pumps also demonstrated the dependence of the pump's stability from the flow. However, this dependence was positive $(r=0.68, p<0.001)$. If at flows $<3 \mathrm{~L} / \mathrm{min}$ the average standard deviation of the developed pressures was $1.8 \pm 0.1 \mathrm{mmHg}$, this parameter significantly rose to $2.2 \pm 0.1 \mathrm{mmHg}$ $(p<0.01)$ at flows $>3.5 \mathrm{~L} / \mathrm{min}$, and reached $2.7 \pm$ $0.3 \mathrm{mmHg}$ at flows $>4 \mathrm{~L} / \mathrm{min}$.

In the case of the Rotaflow, we failed to determine any association of pressure variability and flow $(r=0.21, p>0.05)$.

During experiments with gradual inlet stagnation, all pumps showed the same trends as in experiments with outlet stagnation (Figure 5). However, in these experiments, variability of developed pressure was significantly higher than during the outlet stagnation (Table 1).

All pumps demonstrated an increase of relative temperature at the inlet of the pump (Figure 6). The Rotaflow showed the highest difference in relative temperature between AR01 (before pump) and the AR02 (inlet of pump), $0.57 \pm 0.21^{\circ} \mathrm{C}$. The mean differences in relative temperature in the cases of the BP80 and the DP2 were significantly lower $\left(0.34 \pm 0.21\right.$ and $0.34 \pm 0.17^{\circ} \mathrm{C}$, respectively). All pumps demonstrated a statistically significant association between the rise of relative temperature at the inlet of a pump and the flow rate (BP80 $r=-0.60, p<0.01$; Rotaflow $r=-0.59, p<0.05$; DP2 $r=-0.49, p<0.05)$. However, only in experiments with the BP80 did we find an association between the rise of relative temperature and variability of pressure through the pump $(r=0.90$, $p<0.0001$ ).

In experiments with entire flow stagnation ('zero-flow regime'), all pumps showed rapid rising of temperature difference in $90 \mathrm{~s}$ on $2-4^{\circ} \mathrm{C}$ (Figure 7a,b). The heating of the fluid was more pronounced in experiments with inlet stagnation (Figure 7b). 

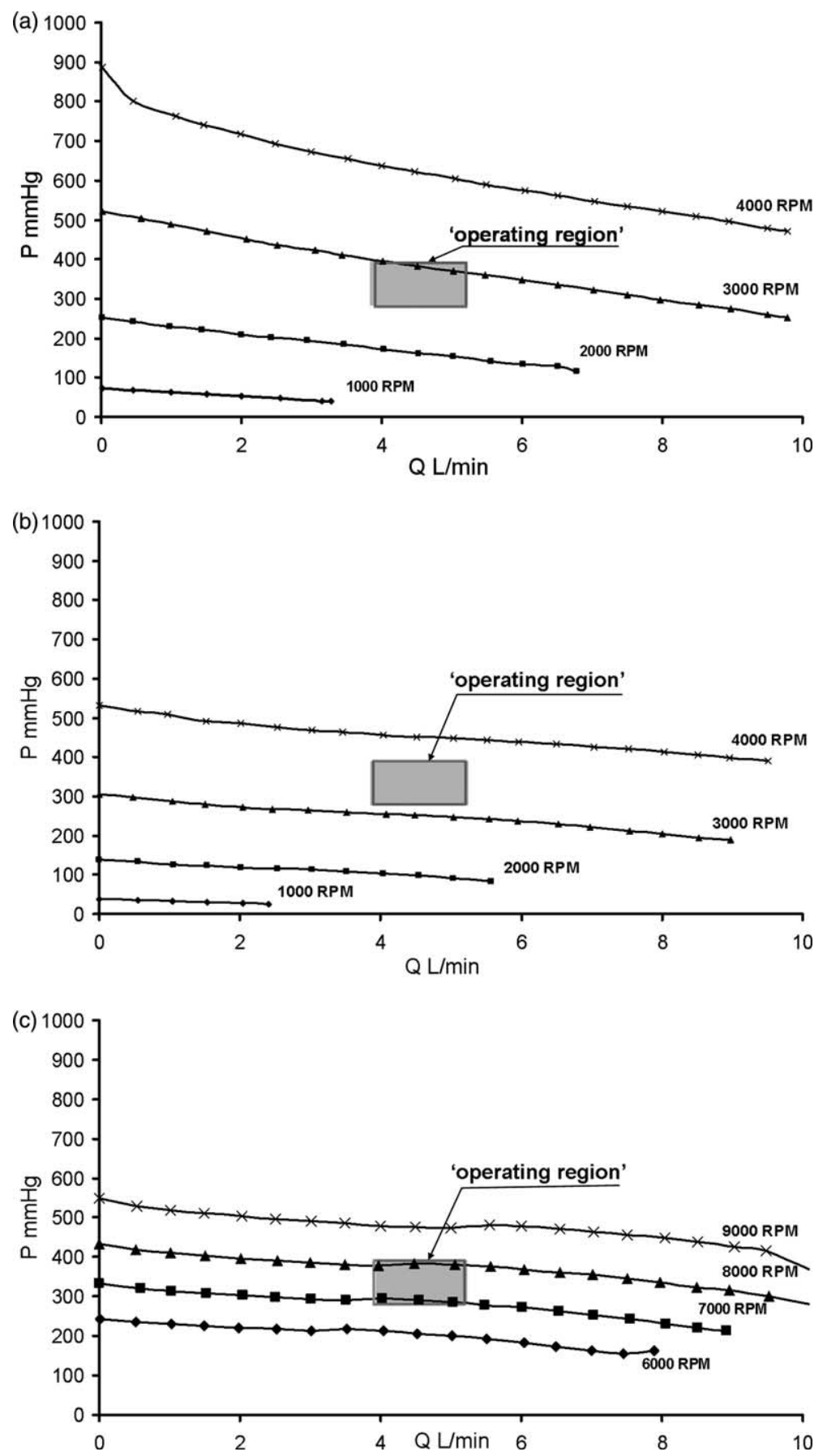

Figure 3 The pressure-flow curves and ‘operating region' of centrifugal pumps. (a) Bio-Medicus Bio-Pump BP80, Medtronic, (b) Rotaflow, Jostra Medizintechnik, and (c) DeltaStream ${ }^{\mathrm{TM}}$ DP2, MEDOS Medizintechnik AQ

The hot area at the base of the DP2 (Figure 2) was an unexpected finding of our study. The relative temperature at the base of DP2 exceeded by $5.5 \pm 0.1^{\circ} \mathrm{C}$ the temperature before the pump in experiments with gradual outlet stagnation. The difference reached was $14.6 \pm 1.2^{\circ} \mathrm{C}$ in experiments with inlet stagnation. The temperature of this area was not related to the flow, but was highly associated with the pump speed $(r=0.91$, $p<0.0001$ ).

\section{Discussion}

CP were thought to be safe, harmless, and easy to operate. Apparently, this is a gross misconception. 


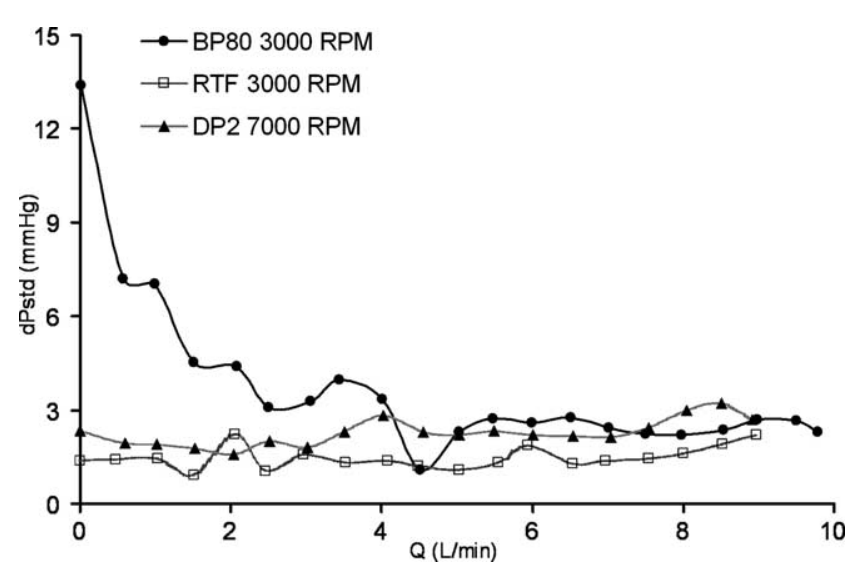

Figure 4 The standard deviation of pressure through the pumps with increasing of outlet resistance and decreasing of produced flow

Several clinical studies are associating the use of $\mathrm{CP}$ with platelet destruction and hemolysis, ${ }^{4,5}$ continuous microemboli during ECMO support, ${ }^{6}$ higher inflammatory response and neutrophil activation. ${ }^{5,7}$ The numerous materials dedicated to the use of industrial CP underline that operating of CP requires a great deal of knowledge and understanding of the hydrodynamics of pumps. ${ }^{2,8}$

Any CP has to be operated inside the so called 'sweet zone'. 'Sweet zone' is defined as an area on the pump's chart where the efficiency of the pump is highest. ${ }^{2}$ The position and size of this area depends on the pump's construction. ${ }^{2}$ The exploitation of the pump outside the 'sweet zone' affects the pump performance. Operating the pump in the area to the right of the 'sweet zone' causes extreme turbulence and classic cavitation. ${ }^{2} \mathrm{~A}$ positive association of pressure variability with flow $(r=0.68, p<0.001)$,

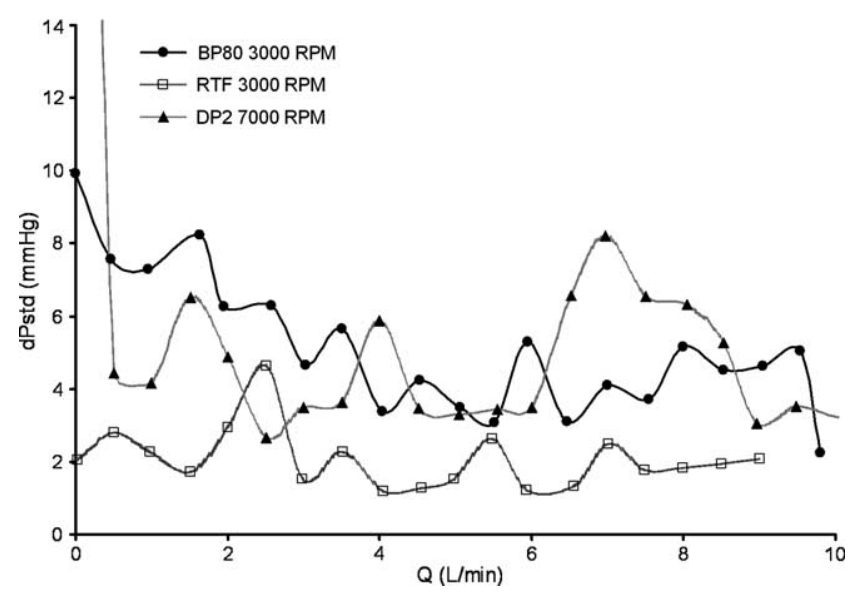

Figure 5 The standard deviation of pressure through the pumps with increasing of inlet resistance and decreasing of produced flow
Table 1 Variability of pressure developed by centrifugal pumps

\begin{tabular}{llll}
\hline Pump & \multicolumn{2}{l}{ Pressure variability (SD) mmHg } & \multirow{2}{*}{$p<$} \\
\cline { 2 - 3 } & Outlet stagnation & Inlet stagnation & \\
\hline BP80 at $3000 \mathrm{rpm}$ & $3.3 \pm 1.5$ & $4.9 \pm 1.6$ & 0.002 \\
Rotaflow & $1.5 \pm 0.4$ & $2.1 \pm 0.8$ & 0.008 \\
DP2 & $2.3 \pm 0.4$ & $4.6 \pm 1.6$ & 0.0001 \\
\hline
\end{tabular}

and a higher variability of pressure developed by the DP2 in our experiments at flows higher than $3.5 \mathrm{~L} / \mathrm{min}$ (pump speed of $7000 \mathrm{rpm}$ ) could be explained by the shifting far to the right from the 'sweet zone'. Our data from the same experiment with the BP80 showed the opposite trend, with incensement of pressure variability with decreasing the flow rate. This fact could be explained by a shift to the left from the 'sweet zone'. If the pump operates to the left from the 'sweet zone' it is very inefficient, with excessive recirculation of fluid inside the pump and cavitation. ${ }^{2}$ The incensement of the internal recirculation and possible cavitation could explain the positive association between the temperature rise and decreasing the flow. This process is especially pronounced in the case of the BP80, where we also found a direct relation of temperature changes with variability of pressure $(r=0.90, p<0.0001)$.

Significantly less stability of all pumps in the study, revealed in experiments with gradual inlet stagnation, could also be explained by the inherited quality of CP. With increasing the negative pressure at the inlet of pump, the situation might arise when pressure in the eye of the impeller falls lower than the vapor pressure of the liquid or saturation pressure of the gas. In this case, vaporous and gaseous cavitation can occur, and

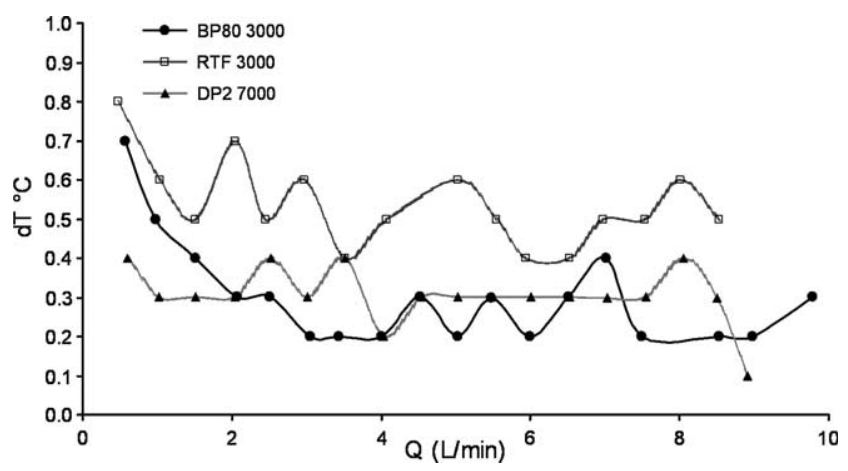

Figure 6 The difference in average of relative temperature between the AR01 (before a pump) and the AR02 (inlet of a pump) with increasing of outlet resistance and decreasing of produced flow. 
the capacity of the pump will be reduced. ${ }^{8}$ The conditions when one or other CP starts to cavitate depend on the construction of the impeller and volute. ${ }^{2}$ The minimum suction pressures higher than the vapor pressure are the pump's minimum requirement curve, an obligatory part of industrial pump charts. As a general guide, the pressure at the suction connection of a pump has to be at least $10 \%$ higher than indicated at the minimum requirement curve. Some experts recommend keeping suction pressure $50 \%$ higher than the minimum required to avoid incipient cavitation. ${ }^{2}$ If, for any reason, suction pressure falls lower than the minimally required, cavitation is unavoidable.

The other inherited characteristic of CP, especially the CP we are using (volute, magnetic drive pumps), is heating up of the pumped fluid. ${ }^{2}$ The heating of pumped fluid always takes place. During exploitation in a 'sweet zone', this rise in temperature is hardly noticeable, and a constant flow through the pump prevents over-heating. However, heat generation dramatically increases if the pump operates outside this zone. Additionally, at shut-off
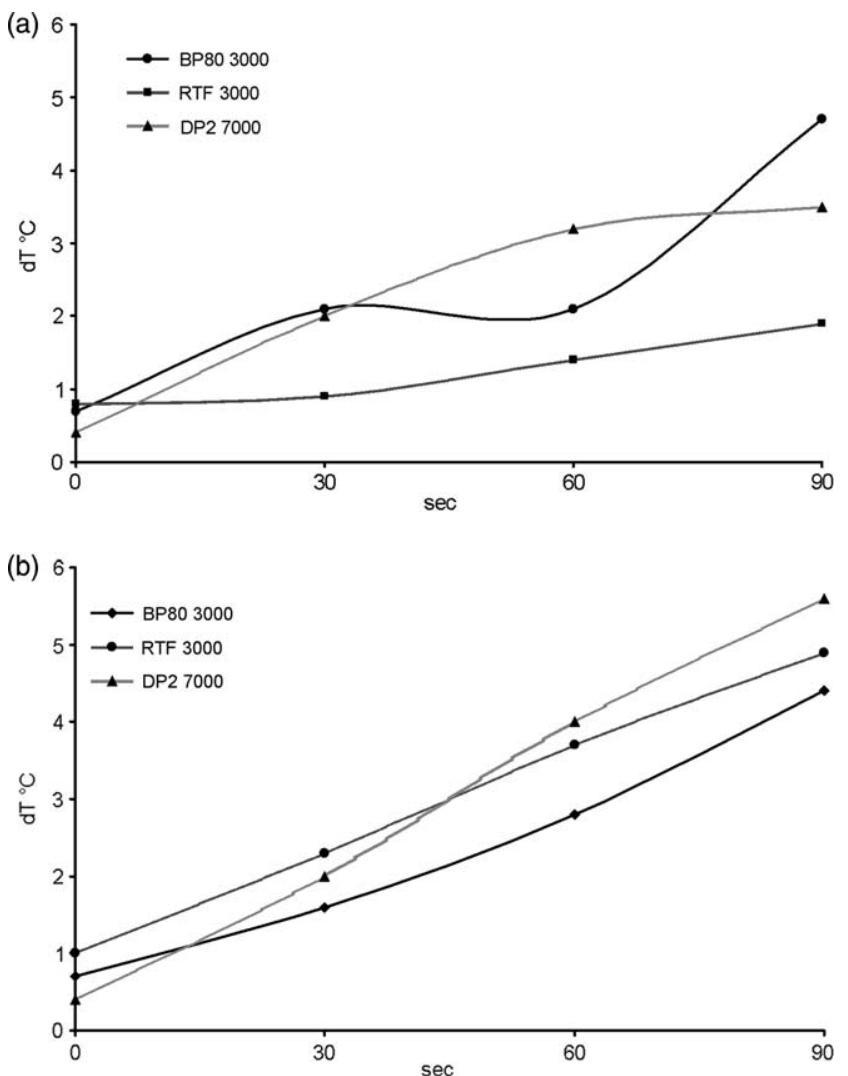

Figure 7 Average of relative temperature difference between the AR01 (before a pump) and the AR02 (inlet of a pump) in 90s of (a) outlet stagnation; (b) inlet stagnation. (zero-flow) regime, all power supplied to a CP (except for small bearing losses) goes to heating the liquid within the pump. The rate of the rise of the temperature depends on the amount of liquid contained in the casing and the power losses (shut off horsepower) of the pump.

More pronounced warming of fluid in experiments with inlet occlusion could also be related to the extensive vapour cavitation near the eye of the impeller. The collapse of bubbles as fluid travels from the start of the impeller vane to its tip is a highenergy exothermic process. Liquid microject of collapse develops pressure $>1 \mathrm{Gpa},{ }^{2,9}$ and the temperature at the point of collapse could reach $5000 \mathrm{~K}^{9}$

We could not find an explanation for the presence of a persistent 'hot' area in the base of the DP2.

\section{Study limitations}

All temperatures in this study are presented as a difference between the relative temperature at the AR01 and AR02. The differences in thermo conductivity of materials at AR01 and AR02 could affect the values of the difference in relative temperature. However, the investigation of all pumps was carried out on the same set and at similar temperature regimes. Hence, the inherited error in deriving temperature difference(s) was the same in all experiments. That is why we believe it is correct to use these values in demonstrating the trends in warming the fluid by CP.

Our literature and experimental study demonstrated that operation of CP is not trouble-free and a simple process. The situation where a CP will be operated outside the allowable region could often appear during clinical perfusion. That is why the constant control of operating conditions and its comparison with a pump performance chart are absolutely necessary for the safe operation of CP.

\section{Conclusion}

(1) The 'zero-flow' regime, described in the manuals of some commercially available pumps, is the use of the pump outside the allowable operating region. It is potentially dangerous and should, therefore, never be used in clinical settings.

(2) Using CP for kinetic-assisted venous return can only be performed safely when the negative pressure at the inlet of the pump is 
monitored continuously. The allowable negative pressure has to be defined for each type of pump and must be based on the pump's performance.

\section{References}

1 Leschinsky B, Itkin G, Zimin N. Centrifugal blood pumps - a brief analysis: development of new designs. Perfusion 1991: 115-21.

2 Bachus L, Custodio, A. Know and understand centrifugal pumps. Elsevier, 2003.

3 Engineers ETPCotAIoC. Centrifugal pumps (Newtonian liquids). A guide to performance evaluation, third edition. American Institute of Chemical Engineers, 2002.

4 Magovern GJ Jr, Simpson KA. Extracorporeal membrane oxygenation for adult cardiac support: the Allegheny experience. Ann Thorac Surg 1999; 68: 655-61.

5 Smedira NG, Moazami N, Golding CM et al. Clinical experience with 202 adults receiving extracorporeal

\section{Acknowledgements}

We would like to thank WJ Smeets for help with textual processing of the manuscript.

membrane oxygenation for cardiac failure: survival at five years. J Thorac Cardiovasc Surg 2001; 122: 92-102.

6 Curtis JJ, Walls JT, Schmaltz RA, Demmy TL, WagnerMann CC, McKenney CA. Use of centrifugal pumps for postcardiotomy ventricular failure: technique and anticoagulation. Ann Thorac Surg 1996; 61: 296-300; discussion 311-13.

7 Baufreton C, Intrator L, Jansen $\mathrm{P}$ et al. Inflammatory response to cardiopulmonary bypass using roller or centrifugal pumps. Ann Thorac Surg 1999; 67: 972-77.

8 Chaurette J. Pump system analysis and centrifugal pump sizing, fifth edition. Fluide Design Inc., 2003.

9 Young F. Cavitation. McGraw-Hill Book Company, 1989. 